\title{
Mosaico
}

FERNANDo RIOS*

DE QUE FAMÍLIA E DE QUE ESCOLA ESTAMOS FALANDO?

O que é a família? Para que serve a família?

0 que é a escola? Para que serve a escola?

0 que existe em comum entre famílias brasileiras (e falamos dos vários Brasis) e as famílias africanas (quantas Áfricas existem?), européias, asiáticas, canadenses, árabes, etc. etc. etc.?

0 que existe de comum entre as escolas espalhadas pelo mundo?

É possível desenhar um modelo universal de família? E de escola?

A sociedade contemporânea se acostumou à velocidade e à velocidade da mudança. Mas parece não se ter dado conta de que a mudança é o fato social mais presente na história da humanidade.

Família e escola, como instituições sociais criadas e consentidas pelo contrato social, não poderiam fugir à regra. E mais, cada família e cada escola se estruturam, exercem-se e se apresentam em suas particularidades.

Família e escola são, foram e serão sempre instituições em mutação. Elas estão em processo de transformação, como de resto toda a sociedade. Por mais que mentalidades fundamentalistas pretendam definir compulsoriamente comportamentos sociais e engessá-los em regras imutáveis.

Família e escola são muito mais dinâmicas do que qualquer decálogo normativo. Pelo fato de elas acontecerem diante de nossos olhos, em situações nas quais estamos inseridos, não costumamos perceber as inúmeras transformações que elas registram. $\dot{E}$ como se olhássemos apenas para um espelho, sem registrarmos nossas imagens passadas. $O$ espelho não revela a mudança. Por isso, o apelo à história da família, à história da educação. Há uma longa trajetória de incríveis mudanças desde a primeira família e a transmissão dos primeiros conhecimentos humanos e a família e a escola contemporâneas.

Certamente, caberá ao poder público adequar as legislações às novas formas de convivência, aprendizagem e socialização. Mas os especialistas em educação e relações familiares têm um papel fundamental nesse processo.

Cada família e cada escola se constituem em universos particulares. Ecomo tal, merecem respostas particulares. Esse parece ser o grande desafio da contemporaneidade.
Para iniciar um processo de reflexão que nos ajude a responder às questões do início deste texto, vamos recorrer a dois autores absolutamente díspares: o promotor de justiça baiano Cristiano Chaves de Farias, no seu texto "Direito à Família", e Bill Gates, o poderoso criador da Microsoft, no capítulo 9 - Educação: o Melhor Investimento - de seu livro A estrada do futuro.

Primeiro, o promotor Cristiano de Farias:

[...] hoje a família é núcleo descentralizado, igualitário, democrático e, não necessariamente heterossexual. Trata-se de entidade de afeto e entre-ajuda, fundada em relações de índole pessoal, voltadas para o desenvolvimento da pessoa humana, que tem como diploma legal regulamentador a Constituição da República de 1988.

$\mathrm{Na}$ medida em que a família deixa de ser encarada sob a ótica patrimonialista e como núcleo de reprodução e passa a ser tratada como instrumento para o desenvolvimento da pessoa humana, realçados seus componentes mais próximos à condição humana, tem-se, sem dúvida, uma democratização da estrutura familiar. São diversas as inquietantes questões que se apresentam no ambiente familiar moderno, gerando perplexidades. A sociedade contemporânea aberta, plural, dinâmica, multifacetária e globalizada não permite mais a afirmação de um modelo fechado de estruturação familiar.

Para finalizar, Bill Gates:

Os educadores, como tantos profissionais na economia atual, são, entre outras coisas, facilitadores. Como muitos outros trabalhadores, terão de se adaptar e readaptar à mudança das condições. Põem, ao contrário de outras profissões, o futuro do magistério parece extremamente promissor. À medida que as inovações melhoraram o padrão de vida, houve um crescimento no segmento de força de trabalho dedicada à educação. Os educadores

\footnotetext{
* Fernando Rıos é jornalista, publicitário, antropólogo e consultor em Comunicação Organizacional Integrada.
} 
que trouxerem energia e criatividade para a sala de aula prosperarão. 0 mesmo acontecerá com os professores que estabelecerem $r$ elações fortes com as crianças, pois elas adoram aulas dadas por adultos que se preocupam genuinamente com elas (p. 235).

[...]

De início, a nova tecnologia da informação apenas incrementará as ferramentas de hoje. Lousas eletrônicas de parede substituirão a escrita a giz da professora por fontes legíveis e imagens coloridas tiradas de milhares de ilustrações educativas, animações, fotografias e vídeos. Documentos de multimídia assumirão alguns dos papéis hoje desempenhados por livros de textos, testes e outros materiais pedagógicos. $\mathrm{E}$, tendo em vista que os documentos de multimídia estarão conectados a servidores da estrada, eles estarão sempre atualizados (p. 241).

[...]

Diferentes ritmos de aprendizagem serão contemplados, pois os computadores serão capazes de dar atenção individual a cada um de seus alunos. As crianças com deficiências de aprendizado estarão particularmente bem servidas. Independentemente de sua capacidade ou deficiência, cada aluno poderá trabalhar em seu ritmo próprio (p. 244).

Compare sua reflexão com a deles. E experimente uma conclusão. Evidentemente, além dos textos desta edição de Cadernos Cenpec, os livros, os filmes, os artigos e os sites que sugerimos aqui poderão ajudar.

\section{FAMÍLIA: REDES, LAÇOS E POLÍTICAS PÚBLICAS}

Ana Rojas Acosta, Maria Amalia Faller Vitale (Organizadoras) INSTITUTO DE ESTUdOS ESPECIAIS DA PUC-SP, 2003.

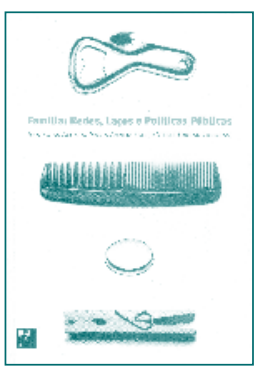

Esta publicação, atualíssima, é a transcrição do seminário com o mesmo título do livro. Com uma grande riqueza de detalhes, esta obra relata reflexões, pesquisas, estudos de caso, agrupados em três vertentes: Vida em Família, Trabalhando com Famílias; Famílias e Políticas Públicas.

Constituiu-se numa realização do IEE-PUCSP; Oficina Municipal da Fundação Konrad Adenauer; Centro de Estudos e Pesquisas em Educação, Cultura e Ação Comunitária - Cenpec; Universidade Cruzeiro do Sul - Unicsul; e contou com o apoio da Fundação Prefeito Faria Lima - Centro de Estudos e Pesquisas de Administração Municipal - Cepam e Fundo das Nações Unidas para a Infância - Unicef.

\section{A ORIGEM DA FAMÍLIA, DA PROPRIEDADE PRIVADA E DO ESTADO}

\section{FRIEDRICH ENGELS}

TRABALHo RELACIONAdo COM AS INVESTIgAÇÕES DE L. H. MoRgan

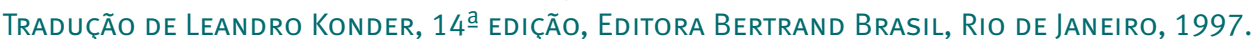

O TEXTO TAMBÉM PODE SER ACESSADO PELO ENDEREÇO: HTTP://WWW.MOREIRA.PRO.BR/CLASSCENT.HTM

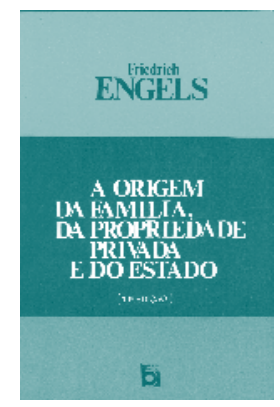

Friedrich Engels (1820/1895) e Karl Marx (1818/1883) formam uma das mais famosas duplas de filósofos de todos os tempos que se complementam. Foram amigos, colaboradores entre si, influenciaram-se mutuamente. Com a falência da antiga União Soviética e queda do muro de Berlim, no dia 9 de novembro de 1989, aumentaram as virulentas e violentas contestações às suas propostas socialistas. Contudo, continuam ícones do pensamento político e econômico. Não é necessário concordar com suas propostas, porém, não se pode ignorá-las.

É o que acontece com este clássico $A$ origem da família..., cuja primeira edição surgiu em 1884. Com base nos estudos e nas teorias do antropólogo americano Lewis Henry Morgan (1818/1881), ele traça um perfil histórico da família desde os tempos das sociedades pré-letradas até o final do século XIX. Um trabalho instigante e que nos ajuda a entender a formação da sociedade ocidental contemporânea.

Seu texto é bastante contundente. 


\section{A POLÍCIA DAS FAMÍLIAS}

JACQUES DONZELOT

PrefÁcio de GiLles DeLEuZE

Tradução de M. T. da Costa Albuquerque, 3aㅡ edição, Edições GraAl Ltda., Rio de Janeiro, 2001.

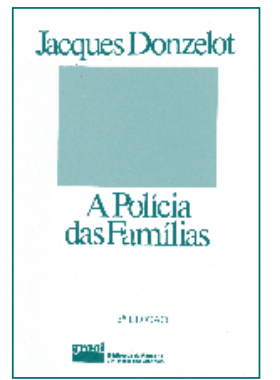

O livro apresenta uma história social da família do século XVIII ao início do século XX. O autor analisa a definição de família, construída pelas camadas burguesas do Antigo Regime, as formas pelas quais essa definição se estendeu a outras classes sociais, o conjunto de tecnologias políticas que investiram sobre o corpo, a saúde e as condições de vida a partir do século XVIII e as transformações no seu conceito, considerando as práticas de atendimento às crianças, a posição da mulher e suas atribuições e a função política do chefe de família.

O livro permite ao professor discutir os papéis familiares e sua relação com as políticas sociais e as formas históricas de organização familiar.

\section{FAMÍLIA \& ESCOLA - TRAJETÓRIAS DE ESCOLARIZAÇÃO EM CAMADAS MÉDIAS E POPULARES}

maria Alice nogueira, Geraldo Romanelli, Nadir Zago (organizadores).

3aㅡ EdiçÃo, Editora Vozes, Petrópolis, RJ, 2007.

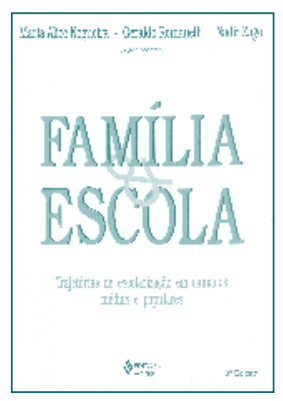

Na apresentação desta coletânea de textos, os autores comentam:

"As famílias, assim como a escola, não podem ser consideradas de forma abstrata, dissociadas de suas condições históricas e socioculturais. Como já tem sido apontado por vários pesquisadores, variam consideravelmente as formas de interação que as camadas médias e as camadas populares estabelecem com os professores e - de modo geral - com a instituição onde estudam seus filhos, ou ainda as práticas que adotam para favorecer a escolarização deles. Explicitar algumas dessas variações é um dos propósitos dos trabalhos aqui reunidos".

Outros temas complementam os objetivos do livro: a escolha do estabelecimento ensino pelas famílias; a divisão do trabalho educativo no seio do casal; a tensão dos pais entre a realização pessoal e a competitividade escolar do filho; o extra-escolar e o lazer dos jovens em suas relações com o mundo escolar; as estratégias familiares de internacionalização dos estudos, verificadas em certos meios sociais.

\section{A RELAÇÃO FAMÍLIA/ESCOLA - DESAFIOS E PERSPECTIVAS}

HELOISA SZYMANSKY

2a EdiçÃo ATUALIZAda, Líber LiVRo, Brasília, 2007.

Um pequeno livro, bem escrito, que serve muito bem às pessoas que estão buscando as primeiras informações ou iniciando seu trabalho no relacionamento escola, família, comunidade, ou para aqueles que pretendem sistematizar seus conhecimentos. É um livro útil até para especialistas.

\section{HISTÓRIA SOCIAL DA CRIANÇA E DA FAMÍLIA}

PHILIPPE ARIÈS

Tradução de Dora Flaksman, 2 2a Edição, lTC - Livros Técnicos e Científicos Editora S. A., Rio de Janeiro, 2006.

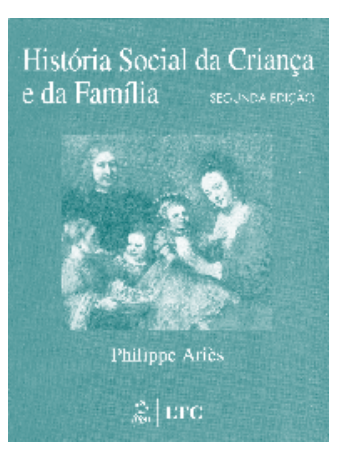

Mesmo refletindo bastante sobre as transformações da criança, da família e da educação nos nossos dias, o título desta obra deveria incluir o complemento que existe no título em francês: L'enfant et l avie familiale sous l'ancien regime. Isso significa que as principais referência de Áries remontam dos séculos XV ao XVIII. Nem por isso, porém, este livro deixa de ser instigante, questionador, indignado. Áries nos diz que, durante muitos séculos, “a criança aprendia as coisas que devia saber ajudando os adultos a fazê-las". Esta obra do grande historiador é um momento de ilustração para quem gosta de educação. Percorrem-se alguns séculos de importantes exemplos familiares e pedagógicos, nem sempre edificantes, por exemplo, “a persistência até o fim do século XVII do infanticídio tolerado”. Um alerta: este trabalho poderá aumentar algumas indignações. 


\section{SITES}

\section{http://escoladafamilia.fde.sp.gov.br/apresentacao.html}

A ESCOLA DA FAMÍLIA

O Programa Escola da Família é uma iniciativa que une mais de 4 mil profissionais da educação, 18.548 estudantes universitários e 20.885 voluntários para criar uma cultura da paz, despertar potencialidades e desenvolver hábitos saudáveis junto aos mais de 7 milhões de jovens que vivem no Estado de São Paulo.

O objetivo do Programa é a abertura, aos finais de semana, de 2.334 escolas da Rede Estadual de Ensino, transformando-as em centro de convivência, com atividades voltadas às áreas esportiva, cultural, de saúde e de trabalho.

\section{http://www.ibge.gov.br/ibgeteen/pesquisas/}

\section{IBGE PESQUISAS}

O IBGE produz uma quantidade e uma variedade enorme de informações sobre o Brasil. Dê um passeio por estas páginas! Você vai encontrar o Brasil em números, gráficos e mapas.

Nesta página, é possível acessar Educação no Brasil e A Família Brasileira.

Há textos e números bastante elucidativos.

\section{http://www.brasilia.unesco.org/}

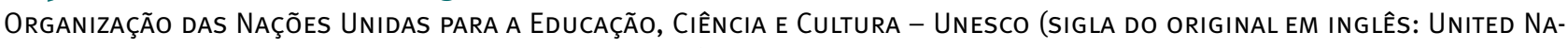
tions Educational, SCIENTific, Cultural Organization)

O site da UNESCO é sempre uma referência quando o assunto é educação. E os trabalhos que o organismo patrocina sempre trazem uma contextualização que contempla a sociedade e a família.

\section{ARTIGOS}

\section{HISTÓRIA DA ESCOLA}

DIÁRIO DO GRANDE ABC, P. 3, SEXTA-FEIRA, 7 DE FEVEREIRO DE 2003.

HTTP://WWW.REDENOARSA.COM.BR/BIBLIOTECA/07SE03_3649.PDF

Em uma página de jornal, uma interessante história da escola. Super-resumida, é verdade, mas útil para se ter uma idéia bem geral.

\section{PARCERIA ESCOLA-FAMÍLIA}

TVE BRASIL SALTO PARA O FUTURO

HTTP://WWW.TVEBRASIL.COM.BR/SALTO/BOLETINS2002/PEF/PEFO.HTM

A TV Escola, canal educativo do Ministério da Educação, produziu uma série de programas sobre a necessidade da Parceria Escola-Família, em 2002. Aqui, são apresentados os textos utilizados nos programas, divididos em:

- Apresentação;

- Nova Família, Nova Escola? - O que há de Novo nas Famílias;

- Sobre Filhos e Alunos - Família: o Ausente Presente dentro da Instituição Escolas;

- Sobre Pais e Professores - Relação família e escola na Educação Infantil: algumas reflexões

- Currículo, escola \& Sociedade - Currículo: um elo importante na parceria escola/família?

- Escola: um espaço em Transformação - Uma visão de futuro 


\title{
COMUNIDADE É A MELHOR PARCEIRA
}

CONVERSAS NA TV ESCOLA

HTTP://MECSRV04.MEC.GOV.BR/SEED/TVESCOLA/REVISTAS/REVISTA20/PDF/ENTREVISTA.PDF

A Secretaria de Educação a Distância, do Ministério da Educação, para apoiar o Programa TV Escola, publica bimestralmente a Revista da TV Escola, distribuída para cada escola integrada ao Programa.

No número 20, a publicação discute a importância de a comunidade estar presente na escola. Na apresentação da reportagem, seu propósito:

Sua presença fortalece a escola, rompe o isolamento dos professores, aperfeiçoa a qualidade do ensino, consolida o projeto pedagógico e dá aos alunos um exemplo de prática da cidadania. Mas como se abre a escola à comunidade?

\section{O QUE MUDOU NA FAMÍLIA BRASILEIRA?}

\section{(DA COLÔNIA À ATUALIDADE)}

ENI DE MESQUita SAMARA

FaCuldade de Filosofia, Letras e CIÊnCIAS HumanAs - USP

HTTP://WWW.SCIELO.BR/SCIELO.PHP?SCRIPT=SCI_ARTTEXT\&PID=S0103-65642002000200004

0 artigo tem por objetivo fazer uma análise comparativa da família brasileira do período colonial até a atualidade, observando as mudanças e as continuidades ao longo do tempo. Tomando como base os recenseamentos da população manuscritos e impressos nos últimos 150 anos, verifica o que realmente ocorreu na sociedade brasileira quanto ao processo de formação de famílias, desenvolvimento econômico e crescimento populacional.

\begin{abstract}
A FAMÍLIA NA HISTORIOGRAFIA BRASILEIRA
BASES E PERSPECTIVAS TEÓRICAS

MARISA TAYRA TERUYA

HTTP://WWW.ABEP.NEPO.UNICAMP.BR/DOCS/ANAIS/PDF/2000/TODOS/A\%20FAM\%C3\%ADLIA\%20NA\%20HISTORIOGRAFIA\%20BR ASILEIRA....PDF

"A História da Família, que no início da década de setenta se apresentava com contornos mal definidos e freqüentemente confundidos com o que poderia ser considerado alguma de suas partes, chegou aos anos noventa renovada, movimentando-se de uma visão limitada da família, como uma unidade estática no tempo, para ser examinada como um processo ao longo da vida inteira de seus membros. Passou do estudo das discretas estruturas domésticas para a investigação das relações da família nuclear com o grupo de parentesco mais vasto e do estudo da família, como uma unidade doméstica distinta, para um exame da interação familiar com os mundos da religião, trabalho, educação, instituições correcionais e sociais e com processos tais como de migração, industrialização e urbanização" (trecho da apresentação do artigo).
\end{abstract}

\section{DIREITO À FAMÍLIA}

CRISTIANO CHAVES DE FARIAS

HTTP://WWW.FACS.BR/REVISTAJURIDICA/EDICAO_MARCO2004/DOCENTE/DOC04.DOC

Em seu texto objetivo e contundente, o autor nos apresenta uma visão contemporânea do fenômeno familiar; as transformações sociais no novo milênio e seus reflelxos na vida familiar; a família na visão jurídica, destacando o tratamento dispensado pela Constituição da República; e propõe um olhar sobre os novos paradigmas da família.

\section{AS OUTRAS FACES DA FAMÍLIA BRASILEIRA}

DORA ISABEL PAIVA DA COSTA

ReSEnha R. BRAS. Est. PoP., CAMPInAS, v. 21, N. 2, P. 349-351, JUL. DeZ. 2004

HTTP://WWW.ABEP.NEPO.UNICAMP.BR/DOCS/REV_INF/VOL21_N2_2004/VOL21_N2_2004_12RESENHA_P349A351.PDF

A professora da Faculdade de Ciências e Letras da Universidade Estadual Paulista - Unesp, Campus Araraquara, faz uma cuidadosa resenha do livro do Professor Paulo Eduardo Teixeira, O outro lado da família brasileira (Editora Unicamp, 2004). Ao mesmo tempo em que comenta o livro, apresenta um belo percurso das transformações da família no Brasil. 